\title{
๑ACORDO DE LENIÊNCIA E O ACORDO DE COOPERAÇÃO TÉCNICA DE AGOSTO DE 2020: \\ PORQUE O MINISTÉRIO PÚBLICO NÃO É (E NÃO DEVERIA SER) SIGNATÁRIO
}

\author{
LENIENCY AGREEMENT AND THE TECHNICAL COOPERATION AGREEMENT \\ OF AUGUST 2020: WHY THE PUBLIC PROSECUTOR'S OFFICE IS NOT (AND \\ SHOULD NOT BE) A SIGNATORY
}

\author{
Shana Schlottfeldt \\ Universidade de Brasília (UnB) \\ Doutora em Informática. Bacharel em Direito. \\ Brasília / DF / Brasil \\ sunb2003@gmail.com
}

\begin{abstract}
Resumo: O presente artigo trata dos motivos que fundamentaram a não adesão do Ministério Público (MP) ao Acordo de Cooperação Técnica (ACT) celebrado em 6 de agosto de 2020, em matéria de combate à corrupção no Brasil, especialmente em relação aos acordos de leniência da Lei n ${ }^{\circ}$ 12.846, de 2013 (Lei Anticorrupção - LAC). Apresenta-se uma série de problemas identificados na modelagem do ACT e, com base nos dados levantados, conclui-se que a decisão do MP em não ser signatário do Acordo, nos termos em que se encontra, foi acertada. Adotou-se para a pesquisa o método dedutivo, com coleta qualitativa de dados bibliográficos. A relevância do tema é evidente diante do cenário global de enfrentamento da corrupção, um processo ainda em construção.
\end{abstract}

Palavras-chave: corrupção; acordo de leniência; Lei Anticorrupção (LAC); Acordo de Cooperação Técnica (ACT).

Abstract: This article deals with the reasons that justified the non-accession of the Brazilian Public Prosecutor's Office (MP) to the Technical Cooperation Agreement (TCA) signed on August 6, 2020, in the fight against corruption in Brazil, especially related to the leniency agreements of the Anticorruption Act (Law 12.846/2013). We present a series of issues identified in the modeling of the TCA, and based on these data, we conclude that the MP's decision not to be a signatory to the Agreement was correct. We adopted the deductive method for the research, with qualitative analysis of bibliographic data. The relevance of the theme is evident in the global scenario of facing corruption.

Keywords: corruption; leniency agreement; anticorruption act; Technical Cooperation Agreement (TCA).

Para citar este artigo (ABNT NBR 6023:2018)

SCHLOTTFELDT, Shana. Acordo de Leniência e o Acordo de Cooperação Técnica de agosto de 2020: porque o Ministério Público não é (e não deveria ser) signatário. Revista Thesis Juris - RTJ, São Paulo, v. 10, n. 2, p. 294-316, jul./dez. 2021. http://doi.org/10.5585/rtj.v10i2.18688. 


\section{Introdução}

Ainda que o conceito de corrupção, stricto sensu, varie de sociedade para sociedade (MELGAR; ROSSI; SMITH, 2010) e possa assumir múltiplas definições e classificações (VARGAS-HERNÁNDEZ, 2009), a corrupção, lato sensu, implica, via de regra, a ação de pelo menos dois pontos: um dentro do ente privado e outro dentro da estrutura pública, em uma relação bilateral configurada pela indevida e irregular troca de benefícios.

Em que pese este estudo ter enfoque no contexto do Brasil, importa mencionar que autores apontam que uma comparação da corrupção entre países e sua disseminação nas esferas pública ou privada permite descobrir diversas semelhanças no modus operandi (JIMÉNEZ; CARBONA, 2012), daí ser natural que se encontre similitudes na maneira de enfrentamento.

No ordenamento jurídico brasileiro, é possível discernir um verdadeiro microssistema anticorrupção (CRISTO; RAMIDOFF, 2017, p. 17; DINO, 2020), com bases constitucionais na configuração do Estado brasileiro, nos direitos fundamentais, nos princípios da Administração Pública, mas também encontrado em dispositivos que delineiam as diversas esferas de responsabilização e sanção, tais como a penal, a civil, a administrativa, e mesmo a política ${ }^{1}$.

As distintas esferas de responsabilização, incidindo sobre o mesmo fato, ainda que autônomas, se inter-relacionam, representando diferentes possibilidades de reparação de danos e uma vasta gama de punição aos agentes públicos e privados que lesarem o Estado, respondendo a distintos fins da proteção do patrimônio público, da moralidade administrativa e do combate à corrupção (OLIVEIRA; SOUSA, 2017, p. 9-10). A opção por um sistema "multiagências", com verdadeira multiplicidade institucional no desempenho das atividades de fiscalização, investigação e punição da corrupção, tem por objetivo "tornar a corrupção empresarial um crime de alto risco e baixo benefício" (FERRAZ, 2015, p. 46; OLIVEIRA; SOUSA, 2017, p. 11-12; BRASIL, 2017b, p. 15; AudTCU et al., 2020, p. 5).

\footnotetext{
${ }^{1}$ Tais dispositivos incluem, mas não se limitam a: o Decreto-Lei no 2.848/1940 (Código Penal); Lei no 1.079/1950 (Lei do Impeachment); Lei no 4.717/1965 (Lei da Ação Popular); Lei no 4.737/1965 (Código Eleitoral); Lei no 8.112/1990 (regime jurídico dos servidores públicos federais); Lei Complementar $\mathrm{n}^{\circ}$ 64/1990 (Lei de Inelegibilidade); Lei ${ }^{\circ}$ 8.429/1992 (Lei de Improbidade Administrativa - LIA); Lei $n^{\circ}$ 8.666/1993 (Lei de Licitações); Lei $n^{\circ}$ 8.730/1993 (que obriga a apresentação e a atualização da declaração de bens na posse em cargos públicos); Lei $\mathrm{n}^{\circ}$ 9.613/1998 (Lei de Lavagem de Dinheiro); Lei $\mathrm{n}^{\circ}$ 9.784/1999 (Lei do Processo Administrativo); Lei Complementar $n^{\circ} 101 / 2000$ (Lei de Responsabilidade Fiscal); Lei Complementar $n^{\circ}$ 135/2010 (Lei da Ficha Limpa); Lei no 12.527/2011 (Lei de Acesso à Informação - LAI); Lei no 12.462/2011 (Lei do Regime Diferenciado de Contratações - RDC); Lei no 12.529/2011 (Lei de Defesa da Concorrência); Lei no 12.813/2013 (Lei de Conflito de Interesses na Administração Pública Federal).
} 
Em complementação e esse microssistema, foi editada, a Lei $n^{\circ} 12.846 / 2013$, a Lei Anticorrupção (LAC), que “dispõe sobre a responsabilização administrativa e civil de pessoas jurídicas pela prática de atos contra a administração pública, nacional ou estrangeira, e dá outras providências" em reconhecimento à constatação que a corrupção, em grande medida, é "fenômeno que passa por organizações, mais do que decorre de iniciativas individuais isoladas [...] envolve práticas reiteradas e complexas redes em que interagem diversos atores sociais, públicos e privados, com alto grau de institucionalização" (BRASIL, 2017a, p. 9).

Este artigo tem por objetivo tratar de um recorte do cenário atual da LAC no que diz respeito ao acordo de leniência e o Acordo de Cooperação Técnica (ACT) celebrado em 6 de agosto de 2020. Mais especificamente, procura-se abordar a questão da não adesão do Ministério Público ao ACT. Entretanto, para chegar a esse ponto específico e contemporâneo, cercado de controvérsias, há que se fazer todo um recorrido.

Este estudo é composto por três capítulos, além desta Introdução e da Conclusão. Tendo mencionado na Introdução o microssistema anticorrupção brasileiro, o Capítulo 1 trata da consolidação do incentivo da resolução de conflitos pela via da consensualidade, abordando as vantagens dos sistemas cooperativos que culminaram na elaboração da LAC. O Capítulo 2 aborda a temática dos acordos de leniência, destacando a importância de uma leitura transversal e ampla da LAC, com vistas a dar efetividade aos acordos de leniência, fortalecendo o alcance do objetivo de combate à corrupção; complementarmente, evidencia-se a necessidade de tratamento especialmente protegido ao colaborador e a questão das múltiplas esferas punitivas/reparadoras, seu impacto na segurança jurídica da celebração de acordos de leniência e a importância da promoção de acordo único, amplo e transversal. O Capítulo 3 apresenta a defesa da legitimidade do Ministério Público na negociação de acordos de leniência, reporta a celebração do Acordo de Cooperação Técnica de agosto de 2020, para apresentar a fundamentação contrária à adesão do Ministério Público aos seus termos, ao que se segue, por fim, a Conclusão.

\section{Do incentivo da resolução de conflitos pela via da consensualidade à Lei Anticorrupção}

Mais recentemente, tem-se aplicado modelos de "detecção e comprovação de desvios a partir de negócios jurídicos de notícia e prova do ilícito por parte do próprio infrator, a incluir a confissão e a consensualidade, através da colaboração premiada na" busca dos demais implicados (BRASIL, 2017a, p. 33). 
Essa ampliação da incidência de institutos negociais de colaboração pode ser observada tanto com a delação ou colaboração premiada, na esfera criminal; quanto com o acordo de leniência, no âmbito civil (SALES; BANNWART JÚNIOR, 2015, p. 33; LEITE; GONÇALVES, 2015, p. 34; DINO, 2020).

A introdução do instituto da delação premiada tem raízes no âmbito da lei sobre crimes hediondos, Lei $n^{\circ} 8.072 / 1990$ (art. $8^{\circ}$, parágrafo único) ${ }^{2}$ (SILVA, 2018, p. 119), que foi ampliado e consolidado em outros diplomas legais, como a Lei $\mathrm{n}^{\circ} 12.850 / 2013$, que define organização criminosa e dispõe sobre a investigação criminal, os meios de obtenção da prova, infrações penais correlatas e o procedimento criminal (SALES; BANNWART JÚNIOR, 2015, p. 33).

Já o instituto de leniência, voltado à preservação da competitividade, existe no Brasil desde 2000, com a Medida Provisória n ${ }^{\circ}$ 2.055/2000, convertida na Lei ${ }^{\circ} 10.149 / 2000$, que dispôs sobre a prevenção e repressão às infrações contra a ordem econômica, no âmbito da atuação do Conselho Administrativo de Defesa Econômica (CADE) (SALES; BANNWART JUUNIOR, 2015, p. 36, 47; RUFINO, 2015, p. 49; DESCHK, 2016, p. 186). Nesse contexto, o acordo de leniência adotou a lógica do "vencedor ganha tudo" servindo como uma importante ferramenta para descobrir e punir cartéis, embora não se restringindo a tal prática, mas também incluindo fraudes em licitações e o crime de participação em organização criminosa conexos a infrações da legislação antitruste (MELLO, 2015, p. 26-29).

A Lei n ${ }^{\circ}$ 13.105/2015 (Novo Código de Processo Civil - CPC) prestigia soluções pela via da consensualidade na resolução de conflitos (CARDOSO, 2018, p. 13), conduta também exaltada na Lei $n^{\circ} 13.140 / 2015$, que dispõe sobre a mediação entre particulares como meio de solução de controvérsias e sobre a auto composição de conflitos no âmbito da administração pública.

Este movimento favorável à consensualidade não pode ser ignorado no âmbito do direito sancionador, de responsabilização civil e administrativa de agentes infratores (CRISTO; RAMIDOFF, 2017, p. 18; CARDOSO, 2018, p. 13), vez que mesmo em matéria penal, ultima ratio do sistema punitivo, há fórmulas de transação consagradas há anos, como as previstas na Lei nº 9.099/1995 (que dispõe sobre os juizados especiais) (BRASIL, 2017a, p. 50).

Além disso, a possibilidade de celebrar acordos relativos à reparação e à sanção entre particulares e o poder público, já figurava em diferentes âmbitos, como com termos de

\footnotetext{
${ }^{2}$ Art. $8^{\circ}$ [...] Parágrafo único. O participante e o associado que denunciar à autoridade o bando ou quadrilha, possibilitando seu desmantelamento, terá a pena reduzida de um a dois terços.
} 
compromisso de cessação (TCC) (DESCHK, 2016, p. 191-192) e com termos de ajustamento de conduta (TAC) (CRISTO; RAMIDOFF, 2017, p. 19).

Esse alicerce legal, que estimula a consensualidade, traz inovações que refletem no direito sancionador estatal para adequá-lo a novos paradigmas, em busca de um resultado mais veloz, abrangente e eficaz, capaz de permitir um verdadeiro enfrentamento da atividade delitiva complexa e organizada (BRASIL, 2017a, p. 34).

Qualquer transgressão cria, comumente, uma assimetria informacional. O infrator sabe mais da própria infração do que qualquer outra pessoa. Além disso, as infrações se tornaram cada vez mais complexas, assumindo proporções grandiosas, estruturas imbricadas, virtualizadas e elaboradas (MARRARA, 2015, p. 511). Daí reconhecer-se institutos que premiam a informação obtida por colaboração do próprio agente infrator (LEITE; GONÇALVES, 2015, p. 34).

Para punir um fato ocorrido, o poder público sancionador precisa ter conhecimento de sua ocorrência e conseguir prová-lo, seguindo o devido processo legal, em qualquer das esferas de responsabilização. Assim, sistemas cooperativos partem de premissas racionais, de bilateralidade de utilidades, nas quais os agentes envolvidos consideram uma modulação de interesses que confira vantagens tanto para o sistema sancionatório (detecção da infração e obtenção de provas válidas e suficientes), quanto para aquele que confessa/colabora (moderação ou isenção de sanções) (SILVA, 2018, p. 135). Em suma, permuta-se informação relevante "sobre infrações que dificilmente seriam detectadas ou comprovadas adequadamente sem a participação do insider, por benefícios legais exculpantes, concedidos pelo Estado ao agente colaborador" (BRASIL, 2017a, p. 46)

Uma vantagem evidente para a Administração Pública advém da fonte de provas que ele representa, da agilidade e economia de recursos na investigação e no trâmite do processo, da redução do tempo para aplicação da sanção e da própria participação do infrator, como elemento importante de prevenção, também buscada pela responsabilização punitiva (BRASIL, 2017a, p. 44).

A LAC tem sido apelidada de "Lei da Improbidade Empresarial", "Lei de Improbidade das Pessoas Jurídicas" e "Lei da Empresa Limpa", em referência às leis semelhantes que se aplicam a pessoas físicas (BRASIL, 2017a, p. 9).

A LAC nasceu sob o influxo de dois fatores: a cultura de corrupção e as manifestações populares de 2013 (BERTONCINI; FERREIRA, 2016, p. 456; CRISTO; RAMIDOFF, 2017, p. 21). Originou-se, portanto, de pressão popular e de iniciativas institucionais de diferentes entes e órgãos estatais, em resposta ao gradual aumento da exigência (interna e externa) por 
ações de combate à corrupção (SALES; BANNWART JÚNIOR, 2015, p. 32; CRISTO; RAMIDOFF, 2017, p. 20). Neste contexto, encontram-se tratados internacionais, endossados pelo Brasil e incorporados ao direito nacional ${ }^{3}$.

Destaque-se que, embora conhecida como Lei Anticorrupção, a LAC não utiliza em seu texto o vocábulo "corrupção", mas expressões como "atos lesivos", "atos contra a Administração Pública" ou "atos ilícitos". Ainda assim, o sentido da lei está, de fato, dirigido ao combate à "corrupção", em especial pelo uso da palavra nos instrumentos internacionais supracitados, que o justificam e fundamentam (BRASIL, 2017a, p. 15-16).

No art. $5^{\circ}$, caput, a LAC define três tipos principais de atos lesivos: (1) que atentem contra o patrimônio público nacional ou estrangeiro; (2) que atentem contra princípios da administração pública; (3) que atentem contra os compromissos internacionais assumidos pelo Brasil. Nos cinco incisos que seguem, são listadas as condutas que os tipificam.

Cumpre mencionar que na esfera civil, a responsabilização de pessoas jurídicas, por atos de corrupção e atentatórios à Administração Pública, já tinha previsão no art. $3^{\circ}$ da Lei $n^{\circ}$ 8.429/1992 (Lei de Improbidade Administrativa - LIA), desde que na condição de partícipes ou beneficiárias das condutas atribuídas a agente público. A partir da LAC, mesmo não identificada a participação de agente público, as empresas podem ser responsabilizadas civilmente, preenchendo uma lacuna de responsabilização antes existente (BRASIL, 2017a, p. $8,13)$.

A LAC buscou também um melhor funcionamento do livre mercado e da concorrência, prevendo programas de integridade e conformidade pela valorização de mecanismos de compliance e engajamento em comportamentos éticos (SILVA, 2018). Some-se a isso, opção pela imputação de responsabilidade objetiva da pessoa jurídica pelos atos lesivos praticados em seu favor, bem como a possibilidade de acordo de leniência e formas de sanção que permitem a sobrevivência da sociedade empresarial (BRASIL, 2017a, p. 9; CRISTO; RAMIDOFF, 2017, p. 28; CARDOSO, 2018, p. 14).

Entretanto, somente após passados quase dois anos da publicação da LAC, foi editado o Decreto $n^{\circ} 8.420 / 2015$, regulamentando-a. O Decreto foi responsável, dentre outras coisas,

\footnotetext{
${ }^{3}$ A saber: (i) Convenção sobre o Combate da Corrupção de Funcionários Públicos Estrangeiros em Transações Comerciais Internacionais, da Organização para a Cooperação e Desenvolvimento Econômico (OCDE) (Decreto $n^{0}$ 3.678/2000); (ii) Convenção Interamericana contra a Corrupção, da Organização dos Estados Americanos (OEA) (Decreto $\left.n^{\circ} 4.410 / 2002\right)$; (iii) Convenção das Nações Unidas contra o Crime Organizado Transnacional (Convenção de Palermo), (Decreto $\mathrm{n}^{\circ}$ 5.015/2004); (iv) Convenção das Nações Unidas contra a Corrupção (Convenção de Mérida), (Decreto $\mathrm{n}^{\circ}$ 5.687/2006).

${ }^{4}$ Art. $3^{\circ}$ As disposições desta lei são aplicáveis, no que couber, àquele que, mesmo não sendo agente público, induza ou concorra para a prática do ato de improbidade ou dele se beneficie sob qualquer forma direta ou indireta.
} 
por especificar e esclarecer sobre o instituto de compliance e o acordo de leniência (SALES; BANNWART JÚNIOR, 2015, p. 32), entretanto, ainda assim, não foram superadas algumas lacunas importantes (CRISTO; RAMIDOFF, 2017, p. 28) (e.g., falta de uma diferenciação no tratamento da leniência prévia e da concomitante às apurações; falta de parâmetros legais objetivos para escalonar a atenuação da pena de multa; a forma "atécnica" para tratar dos legitimados para celebrar leniência etc., o que será referido no capítulo seguinte).

\section{Acordo de Leniência}

A origem do acordo de leniência reporta a 1978, nos Estados Unidos da América. Àquela época, o instrumento já tinha uma racionalidade bastante semelhante à encontrada atualmente, entretanto, ainda que cumpridos os requisitos para celebração do acordo, não havia garantia da concessão. Faltava transparência, previsibilidade e incentivos para induzir a autoincriminação e cooperação. Apenas a partir de 1993, após uma reformulação que deu mais transparência ao instrumento, aumentando as oportunidades e os incentivos para empresa relatar atividades criminosas e cooperar, o acordo de leniência se tornou efetivo. Desde então, em dez anos, já havia ocorrido um aumento de vinte vezes na taxa de aplicação, que teria resultado na quebra de dezenas de grandes cartéis (foco, à época, das operações, devendo-se destacar que práticas anticoncorrenciais e corrupção andam lado a lado) (HAMMOND, 2004).

O acordo de leniência é uma espécie de ato jurídico convencional, que constitui, a um só tempo, técnica especial de investigação e meio de defesa (CARDOSO, 2018, p. 11-12). Tem por base a confissão de práticas irregulares lesivas ao interesse público pela pessoa jurídica que delas se beneficiou e na cooperação voluntária de tal agente que, ao colaborar com o Estado, permite-lhe obter informações e provas, novas e relevantes, com a identificação de materialidade e autoria dos ilícitos cometidos, os quais podem ser sancionados, com reflexos em diferentes esferas de controle e responsabilização estatal (MARRARA, 2015, p. 512). Assim, aumenta-se o nível de eficiência e celeridade das investigações de infrações que, por sua complexidade, natureza e organização, são particularmente difíceis de serem detectadas apenas pela atuação da Administração Pública (ALAN, 2017, p. 203). Por sua vez, a pessoa jurídica infratora, recebe, através do acordo, benefícios legais pela colaboração (singular modalidade de sancionamento por seus atos ilícitos) (BRASIL, 2017a, p. 49-50).

A LAC estabelece, em seu Capítulo V, "Do Acordo de Leniência" os pressupostos para sua celebração, quais sejam (art. 16, caput, I e II, LAC): colaboração efetiva que resulte na “identificação dos demais envolvidos na infração, quando couber", e a "obtenção célere de 
informações e documentos que comprovem o ilícito sob apuração". A seguir, dispõe sobre os requisitos cumulativos para a leniência (art. 16, §1 $1^{\circ}, \mathrm{LAC}$ ): (I) precedência na manifestação de interesse na colaboração; (II) cessação completa de seu envolvimento e participação nos atos lesivos, a partir de quando proposto o acordo; (III) a realização de confissão qualificada pela cooperação, i.e., a admissão de sua participação nos ilícitos, a cooperação plena e permanente com as investigações e desdobramentos legais, inclusive comparecendo, as suas custas, até o fim, aos atos processuais.

A leniência é sanção premial, em perspectiva punitiva transversal. Prevê benefícios legais que consistem na redução ou na retirada das penalidades (art. 16, § $2^{\circ}$, LAC), mas não se trata de anistia, geral e irrestrita, de maneira que a confissão não tem o condão de converter o ato ilícito em lícito, permanecendo o dever de indenização pela lesão causada (art. 16, § $3^{\circ}$, LAC).

A reparação integral do dano, não é, de fato, uma espécie de sanção, mas uma obrigação ex lege: a de restituição de uma situação ao estado anterior ao do dano causado. Na esfera civil, este dever decorre de qualquer ato ilícito praticado, pois, conforme a Lei n 10.406/2002 (Código Civil - CC), a responsabilidade civil extracontratual origina-se da violação ou abuso de direito, acarretando reparação sempre que causado dano (arts. 186, 187 e 927, CC) ${ }^{5}$. Também no contexto da LIA está prevista a obrigatoriedade de reparação do dano ao patrimônio público (art. 12, I, II e III, LIA) ${ }^{6}$, reforçada por dispositivos da LAC (BRASIL, 2017a, p. 102).

\footnotetext{
${ }^{5}$ Art. 186. Aquele que, por ação ou omissão voluntária, negligência ou imprudência, violar direito e causar dano a outrem, ainda que exclusivamente moral, comete ato ilícito.

Art. 187. Também comete ato ilícito o titular de um direito que, ao exercê-lo, excede manifestamente os limites impostos pelo seu fim econômico ou social, pela boa-fé ou pelos bons costumes.

Art. 927. Aquele que, por ato ilícito (arts. 186 e 187), causar dano a outrem, fica obrigado a repará-lo.

Parágrafo único. Haverá obrigação de reparar o dano, independentemente de culpa, nos casos especificados em lei, ou quando a atividade normalmente desenvolvida pelo autor do dano implicar, por sua natureza, risco para os direitos de outrem.

${ }^{6}$ Art. 12. Independentemente das sanções penais, civis e administrativas previstas na legislação específica, está o responsável pelo ato de improbidade sujeito às seguintes cominações, que podem ser aplicadas isolada ou cumulativamente, de acordo com a gravidade do fato: (Redação dada pela Lei no 12.120 , de 2009).

I - na hipótese do art. $9^{\circ}$, perda dos bens ou valores acrescidos ilicitamente ao patrimônio, ressarcimento integral do dano, quando houver, perda da função pública, suspensão dos direitos políticos de oito a dez anos, pagamento de multa civil de até três vezes o valor do acréscimo patrimonial e proibição de contratar com o Poder Público ou receber benefícios ou incentivos fiscais ou creditícios, direta ou indiretamente, ainda que por intermédio de pessoa jurídica da qual seja sócio majoritário, pelo prazo de dez anos;

II - na hipótese do art. 10, ressarcimento integral do dano, perda dos bens ou valores acrescidos ilicitamente ao patrimônio, se concorrer esta circunstância, perda da função pública, suspensão dos direitos políticos de cinco a oito anos, pagamento de multa civil de até duas vezes o valor do dano e proibição de contratar com o Poder Público ou receber benefícios ou incentivos fiscais ou creditícios, direta ou indiretamente, ainda que por intermédio de pessoa jurídica da qual seja sócio majoritário, pelo prazo de cinco anos;

III - na hipótese do art. 11, ressarcimento integral do dano, se houver, perda da função pública, suspensão dos direitos políticos de três a cinco anos, pagamento de multa civil de até cem vezes o valor da remuneração percebida pelo agente e proibição de contratar com o Poder Público ou receber benefícios ou incentivos fiscais
} 
Na celebração de acordo de leniência, a publicidade deve ser observada, permitindo a apuração dos cidadãos, ressalvada a sua restrição temporária nas situações especificas (vez que o acordo é negociado mediante assinatura de termo de confidencialidade, que não pode ser desconsiderado sem prejuízo às finalidades persecutórias) (art. 16, §6º LAC) (BRASIL, 2017a, p. 89).

Não há, nas exigências da LAC (e.g., renúncia à garantia de não autoincriminação, com a admissão de participação no ilícito e cooperação plena e permanentemente com as investigações), violação a direitos ou garantias fundamentais, uma vez que a adesão ao instituto de leniência é um ato voluntário, e as renúncias mencionadas situam-se na esfera da disponibilidade do infrator acusado (SALES; BANNWART JÚNIOR, 2015, p. 43, 48). Ademais, caso seja rejeitada pela autoridade estatal competente, a proposta de acordo de leniência não importa em reconhecimento da prática do ato ilícito investigado (art. 16, $\S 7^{\circ}$, LAC).

Cabe ao Estado atender ao interesse público, avaliando os custos e vantagens do acordo para sua atividade de repressão e defesa do erário. Assim, o interesse público é inerente à celebração do contrato de leniência, verificado pela análise da proporcionalidade e do equilíbrio entre os benefícios legais concedidos ao infrator colaborador e o proveito obtido pelo Estado na investigação (FERRAZ, 2015, p. 40). Só são legitimas as benesses que se justifiquem como necessárias e úteis, adequadas e estritamente proporcionais, o que só pode ser avaliado caso a caso (BRASIL, 2017a, p. 57).

Ressalte-se que o Superior Tribunal de Justiça (STJ) e o Supremo Tribunal Federal (STF) já decidiram que na colaboração premiada em sede penal (conforme citado acima, instituto equivalente ao acordo de leniência da LAC), a sanção premial deve obrigatoriamente ter incidência em favor do agente colaborador caso as informações prestadas tenham tido eficácia, inclusive em razão dos princípios da segurança jurídica e da proteção da confiança (BRASIL, 2004; BRASIL, 2015; DINO, 2020).

Por fim, em caso de descumprimento do acordo por parte do denunciante, reativa-se o potencial sancionador que foi negocialmente suspenso (todas as sanções voltam a incidir) (BRASIL, 2017a, p. 112-114).

O acordo de leniência, seguindo a LAC literalmente, tem previsão única e exclusivamente para o processo de responsabilização administrativa. Assim, é possível que, celebrado acordo de leniência, a pessoa jurídica colaboradora ainda esteja, em tese, sujeita à

ou creditícios, direta ou indiretamente, ainda que por intermédio de pessoa jurídica da qual seja sócio majoritário, pelo prazo de três anos. 
responsabilização judicial das sanções de direito administrativo, que podem ser cumuladas, com outras esferas de responsabilidade, dada a proximidade das condutas tipificadas nas várias esferas do direito sancionador estatal, e.g., como a dos atos de improbidade administrativa (art. 18, 19 e 30, LAC $^{7}$ (BRASIL, 2017a, p. 69-70; 82).

Isso mostra como o acordo de leniência previsto na LAC pode tornar-se obsoleto como ferramenta negocial de combate à corrupção, se não interpretado e empregado de modo transversal e amplo (BRASIL, 2017a, p. 71).

A LAC demorou 13 (treze) anos para ser produzida - contados da aprovação do Decreto $n^{\circ}$ 3.678/2000 (relativo à Convenção sobre o Combate à Corrupção da OCDE) (BERTONCINI; FERREIRA, 2016. p. 457), mas foi submetida a um processo legislativo de certa forma acelerado, resultando em algumas imperfeições ou pontos que merecem uma “clarificação", e.g., falta de uma diferenciação no tratamento da leniência prévia e da leniência concomitante às apurações, a falta de parâmetros legais objetivos para escalonar a atenuação da pena de multa, o possível vício lógico do art. 16, $\S 2^{\circ}$, LAC $^{8}$ (MARRARA, 2015, p. 522; CRISTO; RAMIDOFF, 2017, p. 31-32), a possibilidade de apelação da improbidade em face dos fatos ali considerados ilícitos, a forma "atécnica" usada para tratar dos legitimados para

\footnotetext{
${ }^{7}$ Art. 18. Na esfera administrativa, a responsabilidade da pessoa jurídica não afasta a possibilidade de sua responsabilização na esfera judicial.

Art. 19. Em razão da prática de atos previstos no art. $5^{\circ}$ desta Lei, a União, os Estados, o Distrito Federal e os Municípios, por meio das respectivas Advocacias Públicas ou órgãos de representação judicial, ou equivalentes, e o Ministério Público, poderão ajuizar ação com vistas à aplicação das seguintes sanções às pessoas jurídicas infratoras:

I - perdimento dos bens, direitos ou valores que representem vantagem ou proveito direta ou indiretamente obtidos da infração, ressalvado o direito do lesado ou de terceiro de boa-fé;

II - suspensão ou interdição parcial de suas atividades;

III - dissolução compulsória da pessoa jurídica;

IV - proibição de receber incentivos, subsídios, subvenções, doações ou empréstimos de órgãos ou entidades públicas e de instituições financeiras públicas ou controladas pelo poder público, pelo prazo mínimo de 1 (um) e máximo de 5 (cinco) anos. [...]

$\S 3^{\circ}$ As sanções poderão ser aplicadas de forma isolada ou cumulativa. [...]

Art. 30. A aplicação das sanções previstas nesta Lei não afeta os processos de responsabilização e aplicação de penalidades decorrentes de:

I - ato de improbidade administrativa nos termos da Lei no 8.429 , de 2 de junho de 1992; e

II - atos ilícitos alcançados pela Lei $n^{\circ} 8.666$, de 21 de junho de 1993, ou outras normas de licitações e contratos da administração pública, inclusive no tocante ao Regime Diferenciado de Contratações Públicas - RDC instituído pela Lei $\mathrm{n}^{\circ} 12.462$, de 4 de agosto de 2011.

${ }^{8} \mathrm{O}$ art. $16, \S 2^{\circ}$ da LAC, ao dispor que "A celebração do acordo de leniência isentará a pessoa jurídica das sanções previstas no inciso II do art. $6^{\circ}$ e no inciso IV do art. 19 e reduzirá em até $2 / 3$ (dois terços) o valor da multa aplicável" (grifo meu), abre a possibilidade do acordo de leniência isentar o colaborador da penalidade constante do art. 19, IV, a saber, "proibição de receber incentivos, subsídios, subvenções, doações ou empréstimos de órgãos ou entidades públicas e de instituições financeiras públicas ou controladas pelo poder público, pelo prazo mínimo de 1 (um) e máximo de 5 (cinco) anos". Entretanto, de que adiantaria conceder esse benefício, se a leniência não impedisse que o juiz aplicasse a sanção do art. 19, III ("dissolução compulsória da pessoa jurídica"), i.e., a sua extinção como pessoa jurídica? O que impõe uma reinterpretação da LAC: embora o art. 16 não o diga, a leniência imporia uma imunidade também contra a medida prevista no art. 19, inciso III (MARRARA, 2015, p. 522).
} 
celebrar leniência, inclusive não dizendo expressamente que o Ministério Público tem autoridade para fazer acordo de leniência (BERTONCINI; FERREIRA, 2016. p. 459-471; CONJUR, 2019).

Daí a necessidade de uma leitura sistemática e harmonizadora da legislação no âmbito do direito sancionador, sob a perspectiva dos princípios da eficiência (art. 37, caput, Constituição Federal - CF), da razoabilidade e da proporcionalidade (art. $5^{\circ}, \mathrm{LIV}, \mathrm{CF}$ e art. $2^{\circ}$, Lei no 9.784/1999) (CARDOSO, 2018, p. 12; BRASIL, 2017a, p. 72).

Um dos efeitos mais destacados que a pessoa jurídica colaboradora busca, por meio do acordo de leniência, é a conservação de seu patrimônio e de sua existência material, principalmente quanto à possibilidade de operar no mercado e contratar com o setor público. Outro, não menos importante, diz respeito ao tratamento diferenciado que se lhe deve dispensar na busca do ressarcimento integral dos danos (BRASIL, 2017a, p. 109).

É racionalmente inaceitável, que o colaborador, cuja conduta cooperativa é incentivada, possa vir a receber um tratamento pior do que se não houvesse feito o acordo. A mesma lógica indica não ser admissível que o colaborador possa vir a ter situação mais grave do que a imposta aos demais envolvidos, por ele delatados (MARRARA, 2015, p. 514).

As informações e provas entregues pelo colaborador não devem ser utilizadas contra ele, quer de modo direto, quer de modo cruzado, em casos contra terceiros, vez que caracterizaria ofensa das expectativas de confiança e coerência (CONJUR, 2019). Isto é decorrência dos deveres constitucionais do Estado e de seus princípios, como os de confiança, de boa fé, de lealdade, de moralidade, da finalidade e do devido processo legal. Destarte, o acesso e compartilhamento de dados, informações e documentos, para ser válido e proporcional, só pode ser feito com observância das condições acertadas entre colaborador e Estado-acusador (BRASIL, 2017a, p. 119).

Juridicamente, tem-se consequências distintas para um mesmo fato (punitivas e/ou reparadoras; afetas à pessoa física e/ou à empresa). Verifica-se uma fragmentação de subsistemas sancionadores autônomos, com pressupostos de imputação específicos, (penal, civil e administrativo; neste último, é possível identificar-se linhas diversas, e.g., disciplinar, controle de contas, ações de improbidade administrativa, bem como o modelo sancionador específico da pessoa jurídica, trazido pela LAC) (PODER360, 2018; DINO, 2020).

A depender dos atos praticados, a pessoa jurídica estará sujeita a responsabilidade perante: (1) o órgão da Administração Pública lesado (arts. 86 a 88, Lei nº 8.666/1993 ou art. 47, Lei $n^{\circ} 12.462 / 2011$ ); (2) o CADE (art. 36, Lei no 12.529/2011) (DESCHK, 2016, p. 179182); (3) o Tribunal de Contas da União (arts. 46 e 58, Lei no 8.443/1992). 
Quanto às pessoas físicas, ainda que não sejam destinatárias das sanções da LAC, outras penalidades são aplicáveis, acrescidas ainda da responsabilização na seara penal, no que diz respeito a crimes contra a Administração Pública, e.g., corrupção ativa (art. 333, CP), lavagem de dinheiro ( $\operatorname{art.~}^{\text {o }}$, Lei n ${ }^{\circ}$ 9.613/1998), organização criminosa ( $\operatorname{art.~}^{\circ}$, Lei no 12.850/2013), no caso de fraudes a licitações e contratos os previstos na Seção III, do Capítulo IV, da Lei no $8.666 / 1993$.

Entretanto, para o particular, sua realidade infracional é única. E no contexto do acordo de leniência, há a necessidade de que a multiplicidade de instâncias punitivas seja compatibilizada (CONJUR, 2019). A incidência de diversas esferas autônomas de responsabilização pode converter-se em um elemento de incerteza, impedindo a formalização de acordos ou mesmo favorecendo o uso oportunista dos resultados obtidos com a negociação (MARRARA, 2015, p. 518, 521, 525-526; DINO, 2020).

Deve-se, de preferência, efetuar a negociação de acordo único, que contemple adequadamente os interesses dos celebrantes e do ente estatal considerado como um todo (BRASIL, 2017a, p. 62), ainda que nem sempre a negociação conjunta (com todos os agentes das diferentes searas de punição) seja possível.

Entende-se compatível com o interesse público (e.g., combate célere e eficaz à corrupção pública e à improbidade administrativa), que, em acordo de leniência amplo e transversal, dada a eventual sobreposição de esferas concorrentes, contemple-se a aplicação das penas do direito administrativo sancionador, optando-se pelas de caráter pecuniário em detrimento de outras mais gravosas, considerando-se interpretação condizente com o princípio da proporcionalidade e do non bis in idem (BRASIL, 2017a, p. 86-87).

\section{Legitimidade do Ministério Público na negociação de acordos de leniência e o Acordo de Cooperação Técnica de 6 de agosto de 2020}

Conforme mencionado, na esfera do direito sancionador anticorrupção, é fortemente provável a repercussão criminal dos fatos apurados, como se verifica na descrição das condutas abrangidas (art. $5^{\circ}$ e incisos da LAC).

A LAC reservou a competência para a celebração dos acordos, à entidade publica máxima de cada órgão, contudo, estabeleceu a Controladoria-Geral da União (CGU) como o órgão competente para celebrar os acordos de leniência no âmbito do Poder Executivo federal, bem como no caso de atos lesivos praticados contra a administração pública estrangeira (art. 16, §10, LAC) (MARRARA, 2015, p. 516; OLIVEIRA; SOUSA, 2017, p. 1, 4). Sem embargo, sendo a leniência compreendida e utilizada também como instituto de detecção de infrações, 
não se pode afastar o Ministério Público de todas as suas fases, até como forma de garantia à defesa de maior amplitude das condições pactuadas na colaboração (BRASIL, 2017a, p. 49; OLIVEIRA; SOUSA, 2017, p. 2; CONJUR, 2019).

O Ministério Público, em decorrência de seu perfil constitucional autônomo (art. 127, $\S 1^{\circ}$ e art. $\left.128, \S 5^{\circ}, C F\right)$, tem posição de independência em relação às autoridades administrativas. Além disso, por ser titular exclusivo das ações penais públicas (art. 129, CF), entende-se indispensável sua presença, com atribuição negocial para acordos de leniência, fundamentando a segurança jurídica e a base negocial do acordo, sob pena de não se atingir as finalidades legais buscadas nem ser conferida segurança jurídica ao acordo, pela exclusão indevida do custos legis (BRASIL, 2017a, p. 63, 99).

Ademais, diferente do que ocorre com outros negociadores públicos, limitados a atuar em determinado âmbito material, o Ministério Público por sua característica generalista, sem especialidade temática restritiva, estaria mais apto a atuar em negócios processuais transversais (BRASIL, 2017a, p. 65).

Aliás, chama-se a atenção para o fato da LAC ter estabelecido que sanção aplicável na esfera judicial, através de ação civil pública (Lei 7.347/1985, Lei da Ação Civil Pública LACP), que tem como um de seus legitimados o Ministério Público, pode ser objeto de isenção, como um dos efeitos do acordo de leniência firmado na esfera administrativa (art. 16, $\S 2^{\circ}$, LAC), o que corrobora a necessidade de participação do Ministério Público (BRASIL, 2017a, p. 73).

Outrossim, conferiu-se ao Ministério Público a aplicação das sanções do art. $6^{\circ}$ da LAC, no caso de omissão da autoridade administrativa, o que reforça o entendimento de que as penas nela previstas, inclusive as de seu art.19, são expressão do direito administrativo sancionador, já que ambas podem ser aplicadas na esfera judicial, através de ação civil pública, em caso de omissão da autoridade administrativa (art.19 e 209. LAC). Ou seja, a instância que impõe as sanções não constitui fator que desnatura o caráter de penalidade administrativa. Sob esse prisma, mostra-se perfeitamente possível que uma das pessoas jurídicas que estiverem sob investigação (inquérito civil) ou que figurarem no polo passivo da ação civil pública, proposta consoante o art. $21^{10}$ da LAC, venha a manifestar interesse em celebrar acordo de leniência (FERRAZ, 2015, p. 42; BRASIL, 2017a, p. 74).

\footnotetext{
${ }^{9}$ Art. 20. Nas ações ajuizadas pelo Ministério Público, poderão ser aplicadas as sanções previstas no art. $6^{\circ}$, sem prejuízo daquelas previstas neste Capítulo, desde que constatada a omissão das autoridades competentes para promover a responsabilização administrativa.

${ }^{10}$ Art. 21. Nas ações de responsabilização judicial, será adotado o rito previsto na Lei no 7.347 , de 24 de julho de 1985.
} 
Em dezembro de 2019, foi apresentada pelo Procurador-Geral da República, para apreciação e assinatura, a minuta de um Compromisso de Cooperação, envolvendo sete instituições no enfrentamento à corrupção (Ministério Público Federal - MPF, Advocacia-Geral da União - AGU, Controladoria-Geral da União - CGU, CADE, Comissão de Valores Mobiliários - CVM, Banco Central - BACEN e Tribunal de Contas da União - TCU) (BRASIL, 2020a, p. 7).

Entretanto, em 6 de agosto de 2020, em solenidade realizada por videoconferência, CGU, AGU, Ministério da Justiça e Segurança Pública (MJSP) e TCU celebraram, com a participação do STF, um “Acordo de Cooperação Técnica - ACT em matéria de combate à corrupção no Brasil, especialmente em relação aos acordos de leniência da Lei $n^{\circ}$ 12.846, de 2013", com conteúdo distinto do Compromisso de Cooperação previamente proposto pelo MPF (ACORDO, 2020; AGU, 2020; BRASIL, 2020a, p. 7; BRASIL, 2020b). Na ocasião, o Ministro Dias Toffoli, presidente do STF, anunciou que o Procurador-Geral da República ainda estava analisando o texto do ACT e poderia assiná-lo posteriormente (BRASIL, 2020b; SOUZA, 2020).

O ACT estabelece 7 (sete) princípios gerais aplicáveis em matéria de políticas e atuações estatais anticorrupção; 17 (dezessete) princípios específicos aplicáveis aos acordos de leniência da LAC; 4 (quatro) pilares dos acordos de leniência da LAC; 4 (quatro) ações sistêmicas e 6 (seis) ações operacionais (ACORDO, 2020).

O ACT teve uma repercussão controversa no meio jurídico e na mídia especializada, com alguns apontando a iniciativa como positiva por conferir "maior robustez" ao acordo de leniência e "proteção jurídica ao particular" (AGU, 2020; MUDROVITSCH; NÓBREGA, 2020; BRASIL, 2020b), mas muitos apontando falhas importantes (AudTCU et al., 2020; DINO, 2020; FALCÃO, 2020; FREIRE, 2020; BRASIL, 2020a; ROMANO, 2020), sobre as quais se discorrerá adiante.

Em 10 de agosto de 2020, a Comissão Permanente de Assessoramento para Acordos de Leniência e Colaboração Premiada, da $5^{\text {a }}$ Câmara de Coordenação e Revisão - Combate à Corrupção ( $5^{\text {a }}$ CCR $)$, do MPF, por meio da Nota Técnica $n^{\circ}$ 2/2020, manifestou as razões pelas quais entendia que a Procuradoria-Geral da Republica não deveria aderir ao ACT (BRASIL, 2020a, p. 2). Dentre elas, por entender que o Acordo revelaria incongruências quanto às atribuições constitucionais de cada Instituição no Sistema Brasileiro Anticorrupção, em especial do MPF (BRASIL, 2020a, p. 2, 7), bem como porque endereçaria pontos pendentes 
exclusivamente entre os órgãos que o assinaram, não sendo efetivo quanto à falta de segurança jurídica, para empresas colaboradoras e para o interesse público. Neste sentido (BRASIL, 2020a, p. 44-45):

3. O Acordo de Cooperação Técnica, assinado em 06.08.2020, não oferece uma alternativa de cooperação interinstitucional adequada e respeitosa das atribuições no Sistema Brasileiro Anticorrupção, de modo que não atende o interesse público e não incrementa a segurança jurídica no regime legal dos acordos de leniência, previstos na Lei $\mathrm{n}^{\circ} 12.846 / 2013$;

Em 12 de agosto de 2020, 8 (oito) entidades de referência na área ${ }^{11}$ emitiram Nota Pública de Repúdio ao ACT por representar "inaceitável retrocesso no combate à corrupção", capaz de "colocar o Brasil à margem dos acordos internacionais dos quais é signatário" (AudTCU et al., 2020, p. 1, grifo do original). Inclusive assinalaram que a fim de garantir a estabilidade e a segurança jurídica dos acordos de leniência, dever-se-ia reduzir os legitimados para celebração de "11 mil controles internos na Federação para 28 Ministérios Públicos", instituições autônomas com função constitucional de exercer o combate à corrupção nas esferas civil e criminal, portadoras de independência e dos meios jurídico-processuais "capazes de avaliar a real contribuição dos colaboradores para incrementar as investigações que envolvam desvio de recursos públicos, garantindo-se o compartilhamento, com os Tribunais de Contas e demais órgãos de fiscalização e controle, das informações que não estiverem protegidas pelo manto do sigilo do processo penal" (AudTCU et al., 2020, p. 7, grifos do original; FREIRE, 2020).

Quanto aos problemas presentes no ACT, pode-se apontar:

a) falha insanável na formulação de "balcão único", por ignorar a legitimação do Ministério Público na proteção ao patrimônio público-social e a relação dos acordos de leniência com a responsabilização criminal, afastando inconstitucionalmente o Ministério Público, titular da ação penal (DINO, 2020; BRASIL, 2020a, p. 12; SOUZA 2020).

b) a necessidade de maior abrangência interinstitucional, buscando dar segurança jurídica aos acordos de leniência. Neste ponto, critica-se a exclusão do CADE, do BACEN e da CVM entre os signatários, o que diminuiria o escopo do compromisso

\footnotetext{
11 (1) Associação da Auditoria de Controle Externo do Tribunal de Contas da União (AudTCU); (2) a Associação Nacional dos Auditores de Controle Externo dos Tribunais de Contas do Brasil (ANCT); (3) o Instituto Não Aceito Corrupção; (4) a Associação Nacional dos Procuradores da República (ANPR); (5) a Associação Nacional dos Membros do Ministério Público (CONAMP); (6) o Movimento do Ministério Público Democrático (MPD); (7) a Associação Contas Abertas (Ca); (8) a Confederação Nacional das Atividades Típicas de Estado (CONACATE).
} 
de cooperação por retirar autoridades com atribuição para celebrar outras modalidades de acordo de leniência (o CADE, nos termos da Lei no 12.529/2011 (DESCHK, 2016, p. 186-192); o BACEN e a CVM, nos termos da Lei $\mathrm{n}^{\circ}$ 13.506/2017) aplicáveis em face de um mesmo contexto fático relacionado com casos de corrupção, o que poderia levar à superposição com ilícitos contra a Ordem Econômica, o Sistema Financeiro e o Mercado de Capitais, áreas de competência dessas Instituições (RUFINO, 2015, p. 57-61; DINO, 2020; BRASIL, 2020a, p. 12$14)$.

c) a exposição sintética dos fundamentos normativos do ACT e, em contraposição, a necessidade de ampla fundamentação normativa do marco interinstitucional (incluindo as Convenções Internacionais Anticorrupção, a Constituição Federal, a legislação de cada instituição signatária e a do Acordo de Leniência), a fim de justificar a legitimidade dos compromissos acordados, na ausência de lei específica (BRASIL, 2020a, p. 15-18).

d) a inadequada interpretação isolada e literal da LAC, afastando injustificadamente o MPF de suas atribuições consensuais no campo da legislação anticorrupção criminal, tendo em vista as bases constitucionais e legais do Sistema Brasileiro Anticorrupção (BRASIL, 2020a, p. 18-20).

e) a necessidade de órgão colegiado que viabilize a organização e funcionamento da cooperação interinstitucional, e.g., (1) uma Comissão de Cooperação Interinstitucional: responsável pela execução do objeto do Compromisso de Cooperação, com a reunião de representantes de todas as instituições signatárias, em igualdade de condições, para atividades de articulação, coordenação e cooperação; e (2) Comitês de Cooperação Interinstitucional: cuja composição dependeria da participação institucional requerida no enfrentamento de cada caso concreto (BRASIL, 2020a, p. 20-22).

f) que o ACT tem o STF, na função de "coordenação". Entretanto, o STF, como órgão do Poder Judiciário, deveria afastar-se de qualquer intervenção em negociação e celebração de Acordos de Leniência que poderão ser objeto de decisão judicial posterior, mantendo a equidistância das atividades de apuração (DINO, 2020; BRASIL, 2020a, p. 22-24; ROMANO, 2020). Sobre esse ponto, o Prof. Joaquim Falcão destacou que o Presidente do STF teria extrapolado de suas funções, vez que não teria competência para "promover mediação, negociação ou estratégias 
conjuntas com o Executivo e se comprometer com seu resultado", ao fazê-lo, teria agido com "pretensão a ativismo judicial” (FALCÃO, 2020).

g) o tratamento inadequado do ressarcimento do dano causado ao erário por todo um conjunto de ambiguidades e incertezas que o ACT evoca na sua formulação. O ressarcimento integral deveria ser sempre exigido, variando-se, conforme a circunstância do caso, a ocasião para a devida apuração deste montante. Ademais, o acordo de leniência, não deveria outorgar quitação sem que ocorresse a avaliação adequada do quantum indenizatório devido (BRASIL, 2020a, p. 24-28).

h) a insegurança jurídica criada pelo ACT quanto ao destino dos acordos de leniência anteriormente firmados, ao possibilitar a "adequação" e consequente alteração dos acordos de leniência já firmados ( $c f$. terceira ação sistêmica do ACT) ${ }^{12}$ (BRASIL, 2020a, p. 28-31).

i) a inadequada previsão de compartilhamento genérico e descontextualizado de informação, além da circularização prematura da informação colhida, com o consequente risco de expor precocemente as negociações em curso. Ao que se acresceria a previsão de indevido compartilhamento "obrigatório" de informações obtidas em investigações criminais com órgãos do Executivo (CGU e AGU) e TCU, ferindo a separação de poderes e desconsiderando a conveniência, a oportunidade e os eventuais riscos existentes em cada caso concreto (BRASIL, 2020b, p. 31-32).

j) o indevido padrão obrigatório de benefícios sem correspondência ao caso concreto e a restauração do modelo da Medida Provisória no 703/2015, com vigência encerrada em 29.05.2016 - e cujo teor já vinha sofrendo rejeição no meio jurídico (AJUFE, 2016; ALAN, 2017, 213-220) - em desacordo com o princípio da individualização da resposta do Estado e com reflexos na redução do poder negocial estatal (BRASIL, 2020b, p. 32-34).

k) o desrespeito ao princípio do promotor natural, por possibilitar a escolha da autoridade que a parte acredite ser mais benéfica a ela para apresentar as evidências (BRASIL, 2020b, p. 39).

Assim, de todo o exposto, entende-se como acertada a decisão do MPF de não aderir aos termos do ACT da forma que se encontra. Destaque-se que o próprio MPF reiteradamente

\footnotetext{
${ }^{12}$ Terceira ação sistêmica: adequar os atos normativos e os procedimentos internos de cada partícipe aos termos do presente ACT, devendo envidar esforços no sentido de adequar os acordos de leniência já firmados e os procedimentos em curso. Além disso, as SIGNATÁRIAS DO ACT procurarão, por ato próprio; [...]
} 
manifestou-se favorável à busca de soluções consensuais entre as instituições, inclusive apresentou iniciativa neste sentido (a mencionada minuta de Compromisso de Cooperação), entretanto, a modelagem de cooperação atualmente inscrita no ACT não se mostraria adequada.

\section{Conclusão}

Atos de corrupção demonstram a nítida confusão entre o publico e o privado, a promiscua relação entre Estado e Empresas que afeta o adequado funcionamento da máquina pública, da democracia, do Estado democrático de direito e de suas instituições, cujos efeitos se estendem para além do setor público, podendo ser sentidos no meio social, político e econômico.

A efetividade do combate à corrupção é um processo ainda em construção. No ordenamento jurídico brasileiro, é possível discernir um verdadeiro microssistema anticorrupção. Integrando este microssistema encontra-se a Lei $n^{\circ}$ 12.846/2013 (Lei Anticorrupção - LAC), com o fim de alcançar a pessoa jurídica por atos de corrupção.

Diversos meios de resolução de conflitos têm sido incentivados, o que demonstra a forte tendência que vem se consolidado paulatinamente. A racionalidade envolvida na lógica da consensualidade, aplicada no contexto do direito sancionador e do microssistema anticorrupção, exige, além de esforço interpretativo sistêmico, considerando os valores constitucionais, a reconfiguração do modelo institucional de ativação das distintas esferas de responsabilização jurídica (buscando uma solução à fragmentação organizacional observada com as diversas co-legitimações possíveis). Neste complexo contexto, se insere o instituto do acordo de leniência.

Com o acordo de leniência, o combate à corrupção obtém um instrumento de detecção e prova das infrações, por meio de formas negociadas de colaboração entre infrator e Estado. $\mathrm{O}$ noticiante/colaborador é incentivado ao acordo por um sistema racional de benefícios. Para que o acordo de leniência atinja seus objetivos, é importante que se busque a celebração de acordo único, amplo e transversal.

O Ministério Público, por vários aspectos, dentre os quais seu perfil constitucional autônomo, o fato de ser titular exclusivo das ações penais públicas, portador de meios jurídicoprocessuais, inclusive de investigação, mostra-se como legitimado para celebração de acordos de leniência. Mais do que isso, para que se tenha o mínimo de coerência na formação dos consensos é fundamental que o Ministério Público esteja presente em todas as "mesas de 
negociação", como forma de garantir parâmetros para segurança jurídica da celebração dos acordos.

Em 6 de agosto de 2020, foi celebrado um Acordo de Cooperação Técnica (ACT) em matéria de combate à corrupção, especialmente com relação aos acordos de leniência da LAC, tendo como signatários CGU, AGU, MJSP, TCU e STF, sem contar, entretanto, com a participação do MPF.

O presente estudo compreendeu um recorte que buscou mostrar o acerto do MPF em não assinar o ACT, nos termos em que foi proposto, diante dos diversos problemas por ele apresentados, dentre os quais se pode destacar: (a) falha insanável na formulação de "balcão único" ao afastar o Ministério Público, titular da ação penal, da celebração de acordos de leniência; (b) a necessidade de maior abrangência interinstitucional, buscando dar segurança jurídica aos acordos de leniência; (b.1) a exclusão do CADE, do BACEN e da CVM entre os signatários; (c) a exposição sintética dos fundamentos normativos do ACT, em contraposição, à necessidade de ampla fundamentação normativa do marco interinstitucional; (d) a inadequada interpretação isolada e literal da LAC; (e) a necessidade de órgão colegiado que viabilize a organização e funcionamento da cooperação interinstitucional; (f) o STF constar do ACT na função de "coordenação", sendo que deveria afastar-se de qualquer intervenção em negociação que poderá ser objeto de decisão judicial posterior; (g) o tratamento inadequado do ressarcimento do dano causado ao erário; (h) a insegurança jurídica criada quanto ao destino dos acordos de leniência anteriormente firmados; (i) a inadequada forma de previsão de compartilhamento de informação; (j) o indevido padrão obrigatório de benefícios sem correspondência ao caso concreto, em desacordo com o princípio da individualização da resposta do Estado, redundando em diminuição do poder negocial estatal; (k) o desrespeito ao princípio do promotor natural.

\section{Referências}

ACORDO de cooperação técnica que entre si celebram o Ministério Público Federal, a Controladoria Geral da União (CGU), a Advocacia-Geral da União (AGU, o Ministério da Justiça e Segurança Pública (MJSP) e o Tribunal de Contas da União (TCU) em matéria de combate à corrupção no Brasil, especialmente em relação aos acordos de leniência da Lei $n^{\circ}$ 12.846, de 2013. 2020. Disponível em:

http://www.stf.jus.br/arquivo/cms/noticiaNoticiaStf/anexo/Acordo6agosto.pdf. Acesso em: 14 set. 2020 .

AGU. Advocacia-Geral da União. Acordo de cooperação técnica estabelece parâmetros para negociação e celebração de leniências. Advocacia-Geral da União - Notícias, Combate à Corrupção, 6 ago. 2020. Disponível em: https://www.gov.br/agu/pt- 

de 2020: porque o Ministério Público não é (e não deveria ser) signatário

br/comunicacao/noticias/acordo-de-cooperacao-tecnica-estabelece-parametros-paranegociacao-e-celebracao-de-leniencias. Acesso em: 13 set. 2020.

AJUFE [Associação dos Juízes Federais do Brasil]. Associação dos Juízes Federais do Brasil emite nota pela rejeição da MP da Leniência. 10 mai. 2016. Disponível em: https://www.ajufe.org.br/imprensa/notas-publicas/6681-associacao-dos-juizes-federais-dobrasil-emite-nota-pela-rejeicao-da-mp-da-leniencia. Acesso em: 12 out. 2020.

ALAN, J. A. da S. Z. Novos aspectos relacionados à leniência e à corrupção. Uma abordagem sob a perspectiva da Teoria dos Jogos. Revista de Direito Administrativo, Rio de Janeiro, v. 275, p. 189-222, maio/ago. 2017. Disponível em:

http://www.mpsp.mp.br/portal/page/portal/documentacao_e_divulgacao/doc_biblioteca/bibli_ servicos_produtos/bibli_informativo/bibli_inf_2006/Rev-Dir-Adminis_275.07.pdf. Acesso em: 13 out. 2020.

AudTCU [Associação da Auditoria de Controle Externo do Tribunal de Contas da União]; ANCT [Associação Nacional dos Auditores de Controle Externo dos Tribunais de Contas do Brasil]; Instituto Não Aceito Corrupção; ANPR [Associação Nacional dos Procuradores da República]; CONAMP [Associação Nacional dos Membros do Ministério Público]; MPD [Movimento do Ministério Público Democrático]; Ca [Associação Contas Abertas]; CONACATE [Confederação Nacional das Atividades Típicas de Estado]. Nota Pública de repúdio ao termo de cooperação técnica entre controladores públicos sobre acordos de leniência. 12 ago. 2020. Disponível em: https://static.poder360.com.br/2020/08/Nota-ACTACORDOS.pdf. Acesso em: 14 set. 2020.

BERTONCINI, M. E. S. N.; FERREIRA, D. Atividade Empresarial e Cidadania: Críticas à Lei Anticorrupção Brasileira. Revista Jurídica, [S.1.], v. 3, n. 44, p. 451 - 472, fev. 2016. ISSN 2316-753X. Disponível em: http://revista.unicuritiba.edu.br/index.php/RevJur/article/view/1817/1193. Acesso em: 13 out. 2020.

BRASIL. MPF. Ministério Público Federal. Estudo Técnico n⿳0 01/2017 - 5a CCR. Estudo sobre inovações da Lei no $12.846 / 2013$ - a Lei anticorrupção (LAC) -, e seus reflexos no denominado microssistema anticorrupção brasileiro, com destaque para a adoção de instituto negocial e da ótica da consensualidade no âmbito sancionador, consubstanciada na incorporação normativado acordo de leniência. Análise do instituto, sob aspectos teóricos variados. Avaliação do papel do Ministério Público na celebração de acordos de leniência: legitimidade e alcancede sua atuação. Exame dos efeitos e impactos práticos causados pelo acordo de leniência em sua recente incidência concreta e na interação com as distintas esferas de responsabilização do ordenamento jurídico nacional, 2017a. Disponível em:

http://www.mpf.mp.br/atuacao-tematica/ccr5/publicacoes/estudotecnico/doc/Estudo\%20Tecnico\%2001-2017.pdf. Acesso em: 16 set. 2020.

BRASIL. MPF. Ministério Público Federal. Nota Técnica nº 1/2017 - 5ª CCR. Nota Técnica sobre Acordo de Leniência e seus efeitos, elaborada pela Comissão Permanente de Assessoramento para Acordos de Leniência e Colaboração Premiada, vinculada à $5^{\mathrm{a}}$ Câmara de Coordenação e Revisão do Ministério Público Federal. Brasília, 2017b. Disponível em: http://www.mpf.mp.br/atuacao-tematica/ccr5/notas-tecnicas/docs/nt-01-2017-5ccr-acordo-deleniencia-comissao-leniencia.pdf. Acesso em: 12 out. 2020. 
BRASIL. MPF. Ministério Público Federal. Nota Técnica no 2/2020 - $5^{\mathbf{a}}$ CCR. Nota Técnica da Egrégia $5^{\text {a }}$ Câmara de Coordenação e Revisão (CCR) do Ministério Público Federal (MPF), através de sua Comissão Permanente de Assessoramento para Acordos de Leniência e Colaboração Premiada (CPAALCP), sobre o Acordo de Cooperação Técnica assinado pela Advocacia-Geral da União (AGU), Controladoria-Geral da União (CGU), Tribunal de Contas da União (TCU) e Ministério da Justiça e Segurança Pública (MJSP), em 06.08.2020, com participação do Supremo Tribunal Federal (STF), em matéria de combate à corrupção no Brasil, especialmente em relação aos Acordos de Leniência, da Lei nº 12.846, de 2013. Brasília, 10 ago. 2020a. Disponível em:

http://www.mpf.mp.br/pgr/documentos/NotaTecnicaAcordodeCooperacaoFinal.pdf. Acesso em: 15 set. 2020.

BRASIL. Superior Tribunal de Justiça. Habeas Corpus $\mathbf{n}^{0}$ 35.198/SP. Relator: Ministro Gilson Dipp, $5^{a}$ Turma, Brasília. Julgado em: 28/09/2004. Publicado: DJ 03/11/2004, p. 215. Disponível em:

https://ww2.stj.jus.br/processo/pesquisa/?src=1.1.3\&aplicacao4=processos.ea\&tipoPesquisa=t ipoPesquisaGenerica\&num_registro=200400614357. Acesso em: 29 set. 2020.

BRASIL. Supremo Tribunal Federal. Ministro Dias Toffoli assina acordo de cooperação técnica para combate à corrupção. Notícias STF, 6 ago. 2020b. Disponível em:

http://www.stf.jus.br/portal/cms/verNoticiaDetalhe.asp?idConteudo=449073. Acesso em: 14 set. 2020.

BRASIL. Supremo Tribunal Federal. Habeas Corpus n⿳ 127.483/PR. Relator: Ministro Dias Toffoli. Brasília. Julgado em: 27/08/2015. Publicado: Dje-021, 04/02/2016. Disponível em: https://jurisprudencia.stf.jus.br/pages/search/sjur337159/false. Acesso em: 29 set. 2020.

CARDOSO, H. R. Lei anticurrupção: consensualidade e função social na empresa no acordo de leniência. Anais do VIII Congresso Brasileiro de Direito Empresarial e Cidadania (CONBRADEC), 2018, Curitiba. p. 11-16.

CONJUR. Delatores devem ser protegidos de ações em outras áreas, diz Nicolao Dino. Consultor Jurídico, Estado e Sociedade, 9 jan. 2019. Disponível em:

https://www.conjur.com.br/2019-jan-09/delator-protegido-acoes-outras-areas-nicolao-dino. Acesso em: 13 set. 2020.

CRISTO, V. D. C. D.; RAMIDOFF, L. M. B. Consensualidade na adminstração pública: uma análise do acordo de leniência previsto na lei anticorrupção. Revista de Formas Consensuais de Solução de Conflitos, v. 3, n. 1, p. 16-35, jan/jun. 2017

DESCHK, J. P. V. A formação de cartéis e a proposição de acordos de leniência por parte das empresas autoras de infração à ordem econômica. Revista Brasileira de Direito Empresarial. Curitiba, v. 2, n. 2, p. 177-197, jul./dez. 2016.

DINO, N. Cooperação e parâmetros para [in]segurança jurídica. JOTA, São Paulo, 25 ago. 2020. Disponível em: https://www.jota.info/opiniao-e-analise/artigos/cooperacao-eparametros-para-inseguranca-juridica-25082020. Acesso em: 13 set. 2020.

FALCÃO, J. O Santo nome em vão: Dias Toffoli extrapola com sua pretensão a ativismo judicial presidencial. Folha de S. Paulo, Opinião, 16 ago. 2020. Disponível em: 
SCHLOTTFELDT, Shana. Acordo de Leniência e o Acordo de Cooperação Técnica de agosto de 2020: porque o Ministério Público não é (e não deveria ser) signatário

https://www1.folha.uol.com.br/opiniao/2020/08/o-santo-nome-em-vao.shtml. Acesso em: 14 set. 2020.

FERRAZ, S. A responsabilização na lei anticorrupção. Revista de Direito Administrativo Contemporâneo, São Paulo, v.3, n.18, p. 33-47, maio/jun. 2015. Disponível em:

http://www.mpsp.mp.br/portal/page/portal/documentacao_e_divulgacao/doc_biblioteca/bibli_ servicos_produtos/bibli_boletim/bibli_bol_2006/RDAdmCont_n.18.02.PDF. Acesso em: 13 out. 2020.

FREIRE, S. Instituto Não Aceito Corrupção repudia cooperação técnica sobre acordos de leniência. Poder 360, 13 ago. 2020. Disponível em:

https://www.poder360.com.br/justica/instituto-nao-aceito-corrupcao-repudia-cooperacaotecnica-sobre-acordos-de-leniencia/. Acesso em: 13 set. 2020.

HAMMOND, Scott. Cornerstones of an effective leniency program. Justice News, The United States Department of Justice, nov. 2004, p. 22-23. Disponível em:

https://www.justice.gov/atr/speech/cornerstones-effective-leniency-program. Acesso em: 01 nov. 2021.

JIMÉNEZ, Fernando; CARBONA, Vicente. Esto funciona así: Anatomía de la corrupción en España. Revista Letras Libres, Dossier, p. 8-19, fev. 2012. Disponível em:

https://www.letraslibres.com/mexico-espana/esto-funciona-asi-anatomia-la-corrupcion-enespana. Acesso em: 01 nov. 2021.

LEITE, F. P. A.; GONÇALVES, F. D. L. A. A eficácia do acordo de leniência na operação Lava Jato e sua influência na cultura da empresa contemporânea. Revista do Direito Público, v. 10, n. 3, p. 31-50, set./dez.2015.

MARRARA, T. Acordos de leniência no processo administrativo brasileiro: modalidades, regime jurídico e problemas emergentes. Revista Digital de Direito Administrativo Brasileiro, v. 2, n. 2, p. 509-527, 2015. Disponível em: https://www.revistas.usp.br/rdda/article/download/99195/98582. Acesso em: 20 set. 2020.

MELGAR, Natalia; ROSSI, Máximo; SMITH, Tom W. The Perception of corruption. International Journal of Public Opinion Research, v. 22, n. 1, p. 120-131, mar. 2010. Disponível em: https://academic.oup.com/ijpor/article/22/1/120/666539. Acesso em: 01 nov. 2021.

MELLO, M. A. C. D. Programas de leniência em países membros e parceiros da Organização para Cooperação e Desenvolvimento Econômico. Estudo Técnico. Brasília: Câmara Deputados, Consultoria Legislativa, 2015.

MUDROVITSCH, R. D. B.; NÓBREGA, G. P. D. Acordo de cooperação técnica em leniência: um sinal (ou esperança) de novos tempos. Consultor Jurídico, 14 ago. 2020. Disponível em: https://www.conjur.com.br/2020-ago-14/improbidade-debate-cooperacaotecnica-leniencia-sinal-ou-esperanca-novos-tempos. Acesso em: 13 set. 2020.

OLIVEIRA, Gustavo Henrique Justino de; SOUSA, Otavio Augusto Venturini de. Controladoria-geral da união: uma agência anticorrupção? In: Controle da administração pública. Belo Horizonte: Fórum, 2017. Disponível em: 
https://edisciplinas.usp.br/pluginfile.php/4361988/mod_resource/content/0/OLIVEIRA\%2C\% 20Gustavo\%20Justino\%20de.\%20SOUSA\%2C\%20Otavio\%20Augusto\%20Venturini\%20de. $\% 20$ Controladoria-

Geral\%20da\%20Uni\%C3\%A3o\%2C\%20uma\%20Ag\%C3\%AAncia\%20Anticorrup\%C3\%A7 $\%$ C3\%A3o.pdf. Acesso em: 14 out. 2020.

PODER360. Fragmentação organizacional prejudica acordos de leniência, diz Nicolao Dino. Poder 360, Poder360 Mercado, 27 nov. 2018. Disponível em:

https://www.poder360.com.br/conteudo-patrocinado/fragmentacao-organizacional-prejudicaacordos-de-leniencia-diz-nicolao-dino/. Acesso em: 13 set. 2020.

ROMANO, R. T. Um ato administrativo heterodoxo. Revista Jus Navigandi, v. 25, n. 6259, 20 ago. 2020. ISSN 1518-4862. Disponível em: https://jus.com.br/imprimir/84719/um-atoadministrativo-heterodoxo. Acesso em: 13 set. 2020.

RUFINO, V. S. Análise da conformação normativa do Programa de Leniência Brasileiro à luz da Teoria dos Jogos. Revista de Direito Setorial e Regulatório, v. 1, n. 1, p. 47-64, 18 maio 2015. Disponível em: https://periodicos.unb.br/index.php/rdsr/article/view/19316/17800. Acesso em: 13 out. 2020.

SALES, M. R.; BANNWART JÚNIOR, C. J. O Acordo de Leniência: uma análise de sua compatibilidade constitucional e legitimidade. Revista do Direito Público, v. 10, n. 3, p. 3150, set./dez.2015.

SILVA, R. C. D. Acordo de leniência e compliance: perspectivas no enfrentamento da corrupção empresarial. 2018. Dissertação (Mestrado - Área Tutelas à Efetivação de Direitos Indisponíveis). Fundação Escola Superior do Ministério Público, Porto Alegre.

SOUZA, R. Sem aval de Aras, Toffoli assina acordo com novas regras para leniência: texto abre brecha para o Ministério Público seja excluído do processo de negociação e homologação de acordos com empresas que se envolvem em corrupção. Correio Braziliense, Política, 6 ago. 2020. Disponível em:

https://www.correiobraziliense.com.br/app/noticia/politica/2020/08/06/interna_politica,87902 7/sem-aval-de-aras-toffoli-assina-acordo-com-novas-regras-para-lenienci.shtml. Acesso em: 13 set. 2020.

VARGAS-HERNÁNDEZ, José G. The Multiple Faces of Corruption: Typology, Forms and Levels. Social Science Research Network SSRN, , p. 1-20, out. 2009. Disponível em: https://papers.ssrn.com/sol3/papers.cfm?abstract_id=1413976. Acesso em: 1 nov. 2021. 